\title{
The area of the fault, the dislocation, the stress drop and the seismic moment of the Friuli earthquake of May 6th, 1976
}

\author{
II. Caputo * \\ Received on October $30 t h, 1976$
}

\begin{abstract}
SUmary. - With different approximate mothods are estimated the values of the area of the fault, of the dislocation, of the stress drop and of the seismic moment of the Friuli earthquake of May $6 \mathrm{th}, 1976$. Some considcrations follow on the possibility to forecast the earthquake and on its relation to the subsequent event of september llth.

Rinssuxto. - Con vari metodi approssimati si stimano i valori del. l'area della faglia, della dislocazione, del rilassamento di sforzo a dol momento sismieo relativi al terremoto del Friuli del 6 Magrgio 1976.

I valori determinati coi vari metodi vengono poi confrontati ed analizzati. se ne ded ueono aleune interessanti conclusioni riguardo al terremoto.
\end{abstract}

Among other parameters characterizing earthquakes the stress Irm is of great importance because of its relation to the surface deiormation which may have preceded the earthquakes. The application of static elastic dislocation theory and of linear elasticity theory to the study of surface deformation pryor to faulting and accompaniyng faulting can be associated to observations of surface deformations of the crust pryor to the earthquake and after the earthquakes and give important information on the mechanics of faulting. These studies can also contribute to the studies of earthquake precursor's in both

* Istituto Nazionale di Geofisica, Roma; Istituto di Geofisica, Universitia di Bologna. 
giving the precursor and the estimate of the nature of the expected earthquake.

In the case of the Friuli May 6 th, 1976 earthquake, since measurements of deformation of the crust have not been made pryor to the earthquake, by means of an estimate of the parameters carachterizing the earthquake, we can only check whether a precursor as deformation of the crust was arailable. This can be done by using the area of the fault, the stress drop, the depth of the hypocenter, and the fault plane solution.

The first two of these parameters are usually obtained by consirlering the seismic moment.

The techniques for the computation of the seismic moment are varied, they range from sophysticaterl analysis of the free morles of the Earth and of the surface wares, to the analysis of near focus seismic recorts or accelerograms. When near focus seismic records or accelerograms are not available, and one wants to aroid the cumbersome analysis of the surface waves and of the free modes, one may use approximate techniques which give the area of the fault which causer the earthquake which in turn gives the stress drop or directly the stress ilrop.

The area of the fault which generated the May 6 th, 1976 earthquake in Friuli can be estimated in three ways. From the area coverer by the distribution of the aftershocks (Benioft 1954) (1), from a relation obtained in a model recently proposed by (aputo (7), and from an empirical formula which can be obtained for the italian seismic region relating the magnitule to the size of the isoseismals of various degree. Methorls (I) and (III) sometimes orerestimate the size of the fault and give an underestimated value of the stress drop.

In cases where no other data was available, the area of the fault which caused an earthquake was estimated to be about that containing the epicenters of the aftershocks. The "Bollettino sismico" issued by I.N.G. (1976) $\left({ }^{12}\right)$ gives the distribution of the hypocenters of the aftershocks of the earthquake of May 6 th, 1976 in Friuli. The epicenters fill almost homogeneously an area of about $600 \mathrm{kmsq}$ centered between Trasaghis and Gemona. Using this data we could therefore induce that the malius of the fault (assumed to be circular) which generated the earthquake is about $14 \mathrm{kms}$.

For the second method of estimating the area of the fault generating the earthquakes we must recall a formula relating it to the magnitude, the elastic parameter $\mu$ (assumed $3 \cdot 10^{11}$ for the italian 
regions) and the angle $\theta$ between the direction of the fault and that of the major tectonic force; in case of circular fault of rarlius $R$ the formula can be written (Caputo) $\left(^{7}\right)$

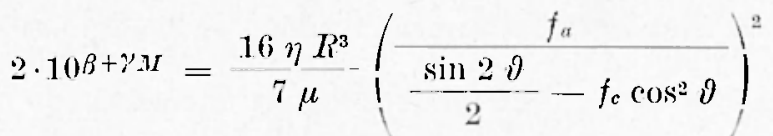

$\eta$ is the seismic efficiency, $\mu$ the rigidity and $f_{a}$ the coliesive force on the sirles of the fault. The stress drop $y$ and the dislocation $s$ are

$$
\begin{gathered}
p=\frac{f_{1 \prime}}{\frac{\sin 2 \vartheta}{2}-\cdot f_{c} \cos ^{2} \vartheta} \\
s=\frac{16 R f_{n}}{\tau \pi \mu\left(\frac{\sin 2 \vartheta}{2}-y_{n} \cos ^{2} \theta\right)}
\end{gathered}
$$

$\beta=12.24, \gamma=1.44$ (Bath, 1973); also for the italian region it has been estimater $f_{a}=10^{5.61}$ (Caputo, $\left.1976 \mathrm{c}\right)\left({ }^{6}\right)$.

The pole of the first nodal plane found by Console (1976) (9) has azimuth $168^{\circ}$ and dip angle $75.5^{\circ}$.

In this solution the Northern Alps would have sinked with respect to the South Eastern Alps; this mechanism is unlikely because lateral compression forces could not cause the slip with such an angle (Caputo $1976 \mathrm{~b})\left(^{\circ}\right)$ while rertical lift caused by isostatic arjustment would cause an earthquake by lifting the Northern Alps.

The pole of the second norlal plane has azimuth of $350^{\circ}$ and dip of $14.5^{\circ}$. This solution in which the Eastern Mlps would have thrusted under the Northern $\Delta l y s$ is more acceptable.

We should note that for value of $\theta$ between $75^{\circ}$ and $90^{\circ}$ the stress drop and the radius obtained from [2] and [1] are very sensitive to small variations of $\vartheta$. Therefore this methorl will be nserl to infer the value of $\vartheta$ from the data obtained with the other methods.

The third method of estimating the area of the fault which generated the earthquake consists in the assumptions that the area the isoseismal of IX regree is roughly equal to that of the fault. The area of IX degree isoseismal has been obtained by Gasparini (1976) $\left({ }^{10}\right)$; it amounts to about $1100 \mathrm{kmsq}$ from which we obtain a radius of $19 \mathrm{kms}$.

Nearly the same value for the area () of the isoseismal of IX dogree could have been obtained immediately from the paper of Caputo et al. (1973) $\left(^{3}\right)$ which gives for the italian region

$$
\log Q=0.79) M+8.07
$$


which is valid in the range $5.5<M<7$; for the magnitude $M=6.2$ we obtain $R=17 \mathrm{kms}$.

From the value of $R$ one may obtain the stress drop $p$ occurred during the earthquake by using the formula of Keilis Borok (1959) (11)

$$
p=\left(\frac{7 E, \mu}{8 \eta}\right)^{1 / 2} n^{-3 / 2}
$$

from which follows for the dislocation

$$
s=\frac{16}{7 \pi \mu} \frac{R p}{\pi \mu}
$$

where $E$ is the elastic energy excited by the earthquake (Bath 1973)

$$
E=10^{12.24+1.44 M}=10 \beta+\gamma, M
$$

and $\mu=3 \cdot 10^{11}$ is the rigidity.

In this note we assumed for the magnitude of the May 6th, 1976 earthquake in Friuli the value 6.2 obtained at the Osservatorio of Monte Porzio Catone (Roma) of the Istituto Nazionale di Geofisica and also the value 6.4 which is the maximum observed in other observatories. In the table are reported the values of $R$ obtained with the two methods and the two values of $M$; in the same table the ralue of the stress drop, of the dislocations and of the seismic moment $M_{0}$ are listed.

It may be noted that the value of the stress drop is consistent with what one may expect for the italian region; the same value would be very common in California.

According to the empirical law [4] one would also obtain in general for the italian region

$$
R=10^{3.786+0.395 M}
$$

which implies for the average stress drop as function of the magnitude using the relation [5]

$$
p=10^{6.15-1 / 2 \log \eta+0.1275 . M}
$$

From the approximate empirical formula used one may also obtain the average dislocation for the italian regions

$$
s=10^{-1.68-1 / 2 \log \eta+0.52 .11}
$$

The seismic moment $H_{0}$ would follow immediately as function of $M$ 
THE AREA OF THE FAULT, THE DISLOCATIOA, NHE STRESS DROP ETC. I7j

$$
M_{\mathrm{o}}=10^{17.87-1 / 2 \log \eta+1.31 M}
$$

Finally, we can find the frequency distribution of the seismic moment which would follow from the frequency distribution of the magnitude. Let $\bar{n}_{0}\left(M_{0}\right) d I_{\mathrm{o}}$ and $\bar{n}(M)$ d $M$ be the number of earthquakes with moment and magnitude in the ranges $M_{0}, W_{\mathrm{o}}+\Delta M_{\mathrm{o}}$ and $M, M+\Delta M$.

Assuming (Caputo), $\left.{ }^{8}\right)$

$$
\begin{aligned}
& \log \bar{n}_{0}=\bar{A}_{02}+\bar{B}_{02} \log M_{0} \\
& \log \bar{n}=\bar{A}_{2}+\bar{B}_{2} M
\end{aligned}
$$

we obtain

$$
\begin{aligned}
& \left.\bar{A}_{02}=\bar{A}_{2}+\frac{v-1}{3} \log \frac{2 u 10 \beta}{\eta p_{2}}-\log \left(\frac{\gamma}{2} \ln 10\right)\right) \\
& \bar{B}_{02}=\frac{\overline{B_{2}}}{\gamma}-1=-\frac{v+2}{3}
\end{aligned}
$$

For the Italian Alps (see Caputo et al., $1973\left({ }^{2}\right)$, area $N$ ) we obtain, for moments in the range $25<\log \mu_{0}<27$ and per year and $1000 \mathrm{kmsq}$

$$
\log \bar{n}_{\mathrm{o}}\left(M_{\mathrm{o}}\right)=-1.68 \log M_{\mathrm{o}}+18.58-0.68 \log \eta p_{2}
$$

where $p_{2}$ is the maximum stress drop. Also we may note that the distribution of faults in this region $\left(R^{-p}\right)$ is inversely proportional to the rolume where the stress drop occurs because $y \sim 3$.

Of all the parameters obtained in this note the most interesting for our purpose is the stress drop. From this value we may deduct two important conclusions, on the possibility to forecast the earthquake of May 6 th, on the consequences of such stress drop at the focal depth of the earthquake which was estimated about $26 \mathrm{kms}$ or less (I.N.G. 1976) $\left(^{12}\right.$ ) and on the dip angle of a supposed Beniofl plane of that area.

We shall first proceed to determine the angle of the dominating tectonic force with the horizontal plane. To obtain this we shall use the determined average values of $p$ presented in the table and formula [2] in which we consider $\vartheta$ as unknown. For $p=8$ bar we obtain $\vartheta=87^{\circ}$. Assuming that there is a Beniofi plane in the area of the earthquake its dip angle in that area is approximately 11.50.

The average value of the stress drop of this earthquake is 8 bars; this implies that pryor to the earthquake there was a stress field. If this was shear it would have implied a deformation on the crust, 
in turn this would have caused a displacement of about $50 \mathrm{~cm}$ on a distance of $20 \mathrm{kms}$. If the stress was a compression the displacement would have been of about $20 \mathrm{cms}$.

The detectability of these displacements depends on two factors. The first is the effect of the surface layers of the crust and of the sediments in transmitting the phoenomenon of the lower layers to the surface. The second is the time needed for the accumulation of the stress. Although these two factors conld put limitations on the possibility to detect the surface effect, the possibility cannot be excluded that precursory phoenomena were detectable on the surface pryor to the earthquake.

Another consequence of the average stress (lrop of about 8 bars at the depth of $26 \mathrm{kms}$ (or less) is the large elastic unbalance created in the upper part of the crust in the vicinity of the fault. This unbalance is generally eliminated by means of the sequence of the aftershocks; in this particular case, when there are faults which are transverse to the one which generated the earthquake, it is very reasonable that in a relatively short period of time another earthquake, of almost the same magnitude of the first, occurs in the transverse fault and nearer to the surface as it was the case of the Friuli sequence.

Table I

\begin{tabular}{|c|c|c|c|c|c|c|}
\hline Method & M & $\underset{\mathrm{km}}{R}$ & $\underset{\text { bar }}{p}$ & $\begin{array}{c}s \\
(\cdot 111\end{array}$ & $\log 3 I_{0}$ & Reference for $R$ \\
\hline I & 6.2 & 14 & 8 & 27 & 25.7 & $\operatorname{ING} 1976\left({ }^{12}\right)$ \\
\hline III a & 6.2 & 19 & 5 & 23 & 25.9 & Gasparini $1976\left({ }^{10}\right)$ \\
\hline III b & 6.2 & 17 & 6 & 25 & 25.8 & (aputo et al. $1973\left(^{3}\right)$ \\
\hline Average & & 17 & 6 & 25 & 25.8 & \\
\hline I & 6.4 & 14 & 11 & 37 & 25.8 & \\
\hline III a & 6.4 & 19 & 7 & 32 & 26.0 & \\
\hline $111 \mathrm{~b}$ & 6.4 & 2] & 9 & 37 & 26.0 & \\
\hline$\Lambda$ verage & & 18 & 9 & 35 & 25.9 & \\
\hline
\end{tabular}

$M=$ Magnitude, $R=$ radlus of the fitult, $p=$ stress $d$ rop (atssuming stress drop to zero), $s=$ displacement, $H_{o}=$ seismic moment (with $n=0.2$ ) for the Friuli event of May $61 \mathrm{~h}, 1976$. 
TIIE AREA OF THF FAULT, THE DISLOCATION, THE RTRESS DROP ETC. 177

\section{REFERENCES}

(1) BENIOFF H., 1954. - Meshanism and strain characteristics of the White Wolf fault as indicated by the aftershock sequence. "Bull. ('al. Dept. of Mines", 171.

(2) Caputo M., 1962. - Tables for the Deformation of an Earth model by surface mass. distribution. "Journ. Geophys. Res.", 67, 4, pp. 1611 1616.

(3) Caputo M., Kemlis-Borok V. I., hronkod T., Molghax G., Paxza G. F., Piva A., Podgaezhaya V., Postpiscril D., 1973. - Model of earthquake oceurrence and isoseismals in Italy. "Annali di Geofisica", XXVI, 2-3, pp. 421-443.

$\left({ }^{4}\right)$ Caputo M., 1976 a. - Properties of earthquales statisties. "Annali di Matematica", 111, 185.

(5) CAPUTO M., 1976b. - Mechanieal models of earthquakes and their statistics. Proceedings E. S. (. Symposium on earthquake risk for nuclear power plant, (1975), "R. Neth. Met. Inst. publ.", 153.

$\left(^{6}\right)$ Caputo M., $1976 \mathrm{c}$ - Mechanical models for the statistics of earthquakes magnitude, moment and jault distribution with stress drop to zero. "Rendic. Ace. Naz. I,incei. Mem. Cl. Se. Mat. Fis. Nat.".

(7) Caputo MI., (In press) - I mechanical model for the statistics of earthqualies magnitude moment and fault distribution. "Bull. Seism. Soc. Am". (Preprint)

${ }^{8}$ ) Caputo M., (Preprint) - Basic properties of distribution of earthqualies magnitude and moment represented in a two dimensional space.

$\left({ }^{9}\right)$ Console R, 1976. - Meceanismo focale del terremoto del Friuli del 6 Maggio 1976. "Annali di Geofisica", XXIX, 3, pp. 165-70.

(10) Gasparini C., 1976. - Parametri ipocentrali dai dati macrosismici del Terremoto del Friuli - Maggio 1976. "Annali di Geofisica", XXIX, 3.

(11) Kruas-Borok V. I., 1959. - On the estimation of the displacement in an earthquale source and of source dimension. "Annali di Geofisica", XII, 2, pp. 205.213.

${ }^{\left({ }^{12}\right)}$ Istituto Nazionale di Geofisiea, 1976. - Supplemento al Bolleftino Sismico definitivo Maggio-(inugno (Friuli, la parte). Settembre, Roma. 